\title{
Smart Intelligent Areca nut and Coconut Theft Detection
}

\author{
Lokesha G.N, M.Tech, PES College of Engineering, Mandya, India, lokeshagoruru@gmail.com \\ Raghavendra babu T.M, Assistant Professor, PES College of Engineering, Mandya, India, \\ raghavendrababu.mandya@gmail.com
}

Abstract The need for an effective and reliable intrusion detection with an alarm system have become vital necessity because of the frequent and rampant cases of burglary. Due to increase of Theft on areca nut and coconut etc, with the advancement in technology, motion can be detected by measuring change in speed or vector of an object in the field of view. This can be achieved either by mechanical devices that physically interact with the field or by electronic device that quantifies and measures changes in the given environment. The motion detector is not only used as intruder alarm but also used in many applications like home automation system, energy efficiency system, etc. According to this project is built using an embedded microcontroller system capable of detecting motion of an intruder in a restricted area and then triggering an alarm system, motion detector system, Sound sensors and accelometric, however passive infrared sensor detected the motion of the person using the person body heat. The passive infrared (PIR) sensor which is the motion detector used in this project is attached to a microcontroller with WIFI which activates the alarm system ,send notification to farmer using IoT it reaches the cloud platforms and any other devices to notify to the farm owner. In addition to PIR sensor we also include accelometric sensor that can be used to read the tiltness of the tree, Sound sensors will be used to read the threshold of ground with any falling of the objects.

Keywords - rampant, areca nut, accelometric, microcontroller, intruder, passive infrared (PIR) sensor, WIFI, tiltnes, IoT(internet of things), threshold.

\section{INTRODUCTION}

The Internet of Things (IoT) is being widely utilized in all areas in farming, robbery Intimation structures lower value and attempt and enhance device flexibility. In Farming gadget there are many interconnected devices for controlling various capabilities inside an area. Mobile devices are portable and it affords a consumer interface in Farming automation gadget. It affords better security machine in which there's excessive degree of theft. This tends to the use of Wi-Fi Module, mobile smart phone and electronics circuit to achieve an automated gadget that's programmed to work as a questioning device to accomplish this reason. In this undertaking movement sensors with lowenergy intake are located wherein an outsider has to skip through. According to the sensor's signals acquired via microcontroller, a call may be send to cell station thru a Wifi modem and therefore warns the presence of unauthorized user in the farm to owner. In recent years theft has been severely increased and there is no protection for people and their assets. Security plays a important function in monitoring a constructing in the absence o presence of human beings. Theft refers back to the crime regarding the taking of someone's assets without their permission. Most of the robbery takes place via door smash-ins. Seventy five\% of theft occurs all through night time. The thief may also take off the fuse, in order that they cannot be without difficulty identified and if they caught, they can be effortlessly escaped. Bluetooth is specifically used to provide the message and the utility that's used to preserve the power while the machine isn't in use. This can even deliver alert to the owner through a cell telephone. In this industrialized international, stealing precious and prosperous matters has end up a critical subject for police and common humans. Theft may additionally mentally have an effect on the human beings because their hard work for years has been misplaced in an unmarried day.

It has following features

1. The device intake power is low: The microcontroller used is Node MCU which consumes less energy.

2. Low value device: The controller and all different sensors are cheaper

3. Friendly user interface 
4. Quick response: Whenever an undesired occasion happens a message can be displayed with in a $2 \mathrm{~d}$ at the phone.

5. Notify the Security Company or the proprietor with the emergency and its kind and notification is executed thru IOT Cloud.

6. System is distinctly correct: Correct status of the sensors is up to date straight away.

7. $24 \times 7$ hours functionality of the gadget.

8. The system is reliable and bendy.

\section{LITERATURE SURVEY}

There are several definitions of automation and security system available in the literature. G. Gu et.al [4] and G. Mingming et.al [5] mentioned that all GSM is one of the most widely used cellular technologies in the world. C. Felix et.al [6], C. Peijiang et.al [7] and B. S. Rao [8] explained that with the increase in the number of GSM subscribers, research and development is heavily supported in further investigating the GSM implementation. Then Rozita Teymourzadeh et.al [9] focused on their [4-8] thoughts and implemented the functionality of GSM protocol for saving the power such as control light, fan and other home appliance. R. Llamas et.al [10] discussed GSM based device control system with mobile application developed using the app inventor for android mobile phones targeting its large market which is able to be helpful for the masses. Then Mahesh N. Jivani et.al [11] used R. Llamas's idea and also has the same functionality as [9] but it includes app inventor for android mobile. But I think, here is no room for security preventing from theft or fire or unwanted situation which is basically the main fact in $21 \mathrm{st}$ century. After that in our research, we are going to explore new ideas \& thoughts which is the combination of saving power and well security system of an organization. For this we are going to use not only GSM but also Bluetooth, web server and android apps to provide a secure organization. Ming Yan et.al [12] proposed and prototyped a new smart living system known as home lighting control system using Bluetooth based android smartphone. Then B. Murali Krishna et.al [13] followed Ming Yan's and represented Bluetooth based wireless home automation system using FPGA. Bluetooth technology, that aims to exchange information wirelessly in a range of short distance by providing a necessary platform to form convenience and controllability. But the fact is, it only works on a limited range but in security matter it also fails to form the long range platform. That's why in our research we use also use Bluetooth along with GSM for long range platform also. Nathan David et.al [14] explored same as the paper [13] but includes more sensors and functionality. It added email notification method but in my point of view we are not that much used to an email but we are pretty much used to in a SMS notification so in our project and paper we use this SMS notification system based on the necessity \& availability. Sirisilla Manohar et.al [15] proposed at planning a basic home automation application on internet through reading the topic of E-mail which is also focused on a single component and as we said before SMS interaction is more compatible than Email. Prof. R.S. Suryavanshi et.al [16] discussed an approach in which a model of Home Automation System using android and WLAN technology, which really offers simple and much awaited Automation Systems. After that Poonam B. Patil et.al [17] used Prof. R.S. Suryavanshi's ideas and proposed a system to control the home appliance using android apps and GSM. In our project we use nearly the same component but the differences is that we have used some additional sensors to protect our organization from unwanted occurrences, fire and theft. Moreover, S.Anusha et.al [18] described the main objective of home automation and security is to assist disabled and old aged those who will alter them to manage home appliances and alert them in critical situations supported android system methodology. V.Persis Priyanka et.al [19] described every person wants his house, industry etc. to be secured. This project describes a security system which will monitor an industry and residential. A PIR sensing element is interfaced to the controller to notice the presence of intruders and instantly captures the image using camera connected to controller and forwards through E-mail and conjointly a buzzer alert is given to intimate others. S. M. Anamul Haque et.al [20] proposed a system that controls the home appliances using the private computer. This system is developed by using the Visual Basic 6.0 as programming language and Microsoft voice engine components for speech recognition purpose. Appliances can be controlled by timer or by voice command. Following S. M. Anamul Haque's idea, Amrutha S et.al [21] proposed a system that described the voice recognition method by which the home appliances can be controlled.

\section{PROPOSED SYSTEM}

This application works as an automatic incident control utility that intimates the person if any stranger entry of their farm during the owner absence. Modules used here are as follows, and fig 1will shows the functional diagram of this system.

1. Arduino UNO Board

2. PIR Sensor

3. Wi-Fi Module

4. Server facet

\section{Arduino UNO Board}

1. The Arduino Uno is a microcontroller board based on the ATmega328 (datasheet). It has 14 digital enter/output pins (of which 6 may be used as PWM outputs), 6 analog inputs, 
a $16 \mathrm{MHz}$ crystal oscillator, a USB connection, a strength jack, an ICSP header, and a reset button. It contains the whole lot needed to aid the microcontroller; really connect it to a laptop with a USB cable or energy it with a AC-toDC adapter or battery to get started. The Uno differs from all previous boards in that it does now not use the FTDI USB-to-serial motive force chip. Instead, it functions the Atmega8U2 programmed as a USB-to-serial converter.

2. "Uno" approach one in Italian and is known as to mark the upcoming release of Arduino 1.0. The Uno and model 1.0 could be the reference versions of Arduno, transferring forward. The Uno is the cutting-edge in a series of USB Arduino boards, and the reference model for the Arduino platform.

\section{PIR Sensor}

1. The PIR sensor stands for Passive Infrared sensor. It is a low value sensor which could locate the presence of Human beings or animals. There are crucial substances gift in the sensor one is the pyroelectric crystal that can come across the warmth signatures from a dwelling organism (humans/animals) and the opposite is a Fresnel lenses that may widen the range of the sensor. Also the PIR sensor modules provide us a few options to regulate the running of the sensor.

2. The two potentiometers (orange colour) are used to manipulate the sensitivity and cause on time of the sensor. Basically the Dout pin of the sensor is found in between the $\mathrm{Vcc}$ and Gnd pins. The module works on three.3V but can be powered with $5 \mathrm{~V}$ as nicely. On the pinnacle left corner it additionally has a cause pin setup which may be used to make the module work in two extraordinary modes. One is the " $\mathrm{H}$ " mode and the alternative is the " $\mathrm{I}$ " mode.

In " $\mathrm{H}$ " mode the output pin Dout will pass high $(3.3 \mathrm{~V})$ whilst a person is detected within range and is going low after a particular time (time is set by potentiometer). In this mode the output pin will pass high irrespective of whether the individual remains gift inside the variety or has left the location. We are the usage of our module in " $\mathrm{H}$ " mode in our undertaking.

3. In "I" mode the output pin Dout will move high (three.3V) when someone is detected inside variety and could live excessive as long as he/she remains inside the restrict of the Sensors variety. Once the individual has left the area the pin will pass low after the particular time which may be set the use of the potentiometer.

\section{WI-FI Module}

1. The ESP8266 WiFi Module is a self-contained SOC with integrated TCP/IP protocol stack that could deliver any microcontroller get right of entry to in your WiFi network. The ESP8266 is capable of both hosting an application and offloading all Wi-Fi networking functions from another software processor. Each ESP8266 module comes preprogrammed with an AT command set firmware, meaning, you could actually hook this up for your Arduino device and get about as lots WiFi-capability as a WiFi Shield gives (and that's just out of the box)! The ESP8266 module is an exceedingly fee effective board with a massive, and ever developing, network.

2. This module has a effective enough on-board processing and storage functionality that permits it to be integrated with the sensors and other software particular gadgets through its GPIOs with minimal development up-the front and minimum loading in the course of runtime. Its high diploma of on-chip integration allows for minimum external circuitry, inclusive of the front-quit module, is designed to occupy minimum PCB vicinity. The ESP8266 helps APSD for VoIP programs and Bluetooth co-existence interfaces, it incorporates a self-calibrated RF permitting it to work below all working conditions, and calls for no outside RF components.

3. There is an almost infinite fountain of statistics to be had for the ESP8266, all of which has been provided with the aid of tremendous network aid.

\section{Server Side}

1. The notification sends by means of the server is obtained and displayed inside the form of alert to the user cell phone.

2. The alert message is notification to the account which has been stored by means of the consumer within the server.

3. Hence the alert notification might be dispatched to the owner of the farm.

4. GUI to real time tracking.

Block Diagram of Proposed System:

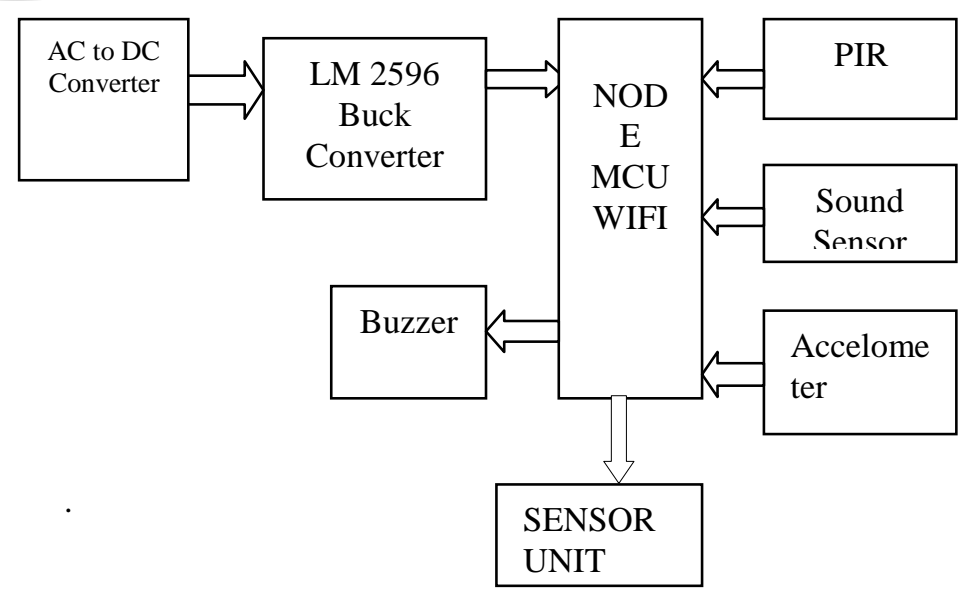

Fig 1. Proposed System

\section{ADVANTAGES}

1. The device intake strength is low: because the microcontroller consumes much less energy. 
2. Low cost machine: controller and all other sensors are inexpensive.

3. Friendly consumer interface.

4. Quick reaction: each time the event occurs a message could be displayed with in a second on the telephone.

5. Notify the Security firm or the owner with the emergency and its kind and notification is finished thru IOT Cloud.

6. System is enormously correct: Correct status of the sensors is updated at once.

7. $24 \times 7$ hours capability of the machine.

8 . The system is reliable and bendy.

\section{DIS ADVANTAGES}

1. Installing of accelometer sensor to each tree is difficult. And also time consuming.

2. Selection of places for the sound sensor is quite difficult.

3. If control unit get fail will fails the whole system.

\section{HARDWARE AND SOFTWARE COMPONENTS REQUIRED}

\section{Hardware Requirements:}

1. Node MCU

2. Microphone Sound Sensor

3. MPU-6050 3-Axis Accelerometer and Gyro Sensor

4. PIR Motion Sensor Detector Module HC-SR501

\section{Software Requirements:}
1. Arduino IDE
2. Blynk IOT
3. Embedded C
4. Android Application

\section{Performance analysis}

Efficient: this system efficient because it sends the message every time when the event occurs.

Availability: this system functionality avails $24 * 7$ hours.

Fast: this system sends messages to the user when event occurs within a second.

\section{Result}

Former will gets the notification to his/her mobile when intruder will enter in to the farm, and buzzer will sounds alarm on the same.

Suppose if the person enters in to farm without permission and try to climb the tree then also buzzer will sounds alarm and notification will sent to the farm owner's android system.

\section{Conclusion}

The Enables the formers will avoid the thief from the theft. Formers will provide the security to their forms.

And formers will come out from the losses which are due to theft. And this system can also be used by the small scale farmer because this system is less costly and it consumes less power supply.

System capable of detecting motion of an intruder in a restricted area very easily and then triggering an alarm system. WIFI which activates the alarm system, send notification to farmer using IoT, so farmer will awake early and can stops the losses.

\section{REFERENCES}

[1] D. Giusto, A. Iera, G. Morabito, L. Atzori (Eds.), The Internet of Things, Springer, 2010. ISBN: 978-1-4419- 1673-0.

[2] Li Da Zu" Internet of Things in Industries: A Survey" IEEE Transactions on Industrial Informatics, vol. 10, no. 4, November 2014

[3] N. Sklavos, P. Kitsos, O. Koufopavlou, "VLSI Design and Implementation of Homophonic Security System", proceedings of IEEE Computer Society Annual Symposium on VLSI (IEEE ISVLSI'12), Amherst, USA, August 19-21, 2012

[4] G. Gu and G. Peng, "The survey of GSM wireless communication system," in Proc. 2010 International Conference on Computer and Information Application (ICCIA), Tianjin, pp.121 - 124.

[5] G. Mingming, Shaoliangshan, Huixiaowei, and Sunqingwei, "The System of Wireless Smart House Based on GSM and ZigBee," in Proc. 2010 International Conference on Intelligent Computation Technology and Automation (ICICTA), Changsha, pp.1017 - 1020.

[6] C. Felix and I. J. Raglend, "Home automation using GSM," in Proc. 2011 International Conference on Signal Processing, Communication, Computing and Networking Technologies (ICSCCN), Thuckafay, pp.1519.

[7] C. Peijiang and J. Xuehua, "Design and Implementation of Remote Monitoring System Based on GSM," in Proc. 2008 Pacific-Asia Workshop on Computational Intelligence and Industrial Application (PACIIA '08), Wuhan, pp.678 - 681.

[8] B. S. Rao, S. D. V. Prasad, and R.M. Mohan, "A prototype for Home Automation using GSM technology," in Proc. 2010 International Conference on Power, Control and Embedded Systems (ICPCES), Allahabad, pp.1-4.

[9] Rozita Teymourzadeh, CEng, Member IEEE/IET, Salah Addin Ahmed, Kok Wai Chan, and Mok Vee Hoong Faculty of Engineering, Technology \& Built Environment UCSI University Kuala Lumpur, Malaysia "Smart GSM based Home Automation System", 2013 IEEE Conference on Systems, Process \& Control (ICSPC2013), 13 - 15 December 2013.

[10] R. Llamas, R Reith, M. Shiere, "Apple Cedes Market Share in Smartphone Operating System Market as Android Surges and Windows Phone Gains, According to IDC", 7th August 2013, IDC Press Release, http://www.idc.com/getdoc.jsp?containerId=prUS242574 13.

[11] Mahesh N. Jivani, "GSM Based Home Automation System Using App-Inventor for Android Mobile Phone", International Journal of Advanced Research in Electrical, Electronics and Instrumentation Engineering (An ISO 3297: 2007 Certified Organization) Vol. 3, Issue 9, September 2014.

[12] Ming Yan, Hao Shi, "Smart Living Using Bluetoothbased Android Smartphone", International Journal of Wireless \& Mobile Networks (IJWMN) Vol.5, No. 1.

[13] B. Murali Krishna, V. Narasimaha Nayak, K. Ravi Kishore Reddy, B. Rakesh, P. Manoj Kumar, N.Sandhya, "Bluetooth Based Wireless Home Automation System Using FPGA", Journal of Theoretical and Applied Information Technology, 31st July 2015. Vol.77. No.3

[14] Nathan David, Abafor Chima, Aronu Ugochukwu, Edoga Obinna, "Design of a Home Automation System Using Arduino", International Journal of Scientific \& Engineering Research, Volume 6, Issue 6, June2015. 